\title{
FRANCISCO AYALA Y EL ENSAYISMO ARGENTINO
}

\author{
Francisca Noguerol Jiménez
}

\begin{abstract}
A mí, el ejercicio de la crítica me es connatural. Aunque no la escribiera, la ejercitaría constantemente como lector, y la aplicaría, desde luego, a mis propias invenciones...

Estudiar a otros autor es, al mismo tiempo, reflexionar sobre la materia de la propia obra.
\end{abstract}

Francisco Ayala ${ }^{1}$

El párrafo que acabamos de citar revela la importancia de la crítica en los textos de Francisco Ayala, quien manifiesta su propia cosmovisión literaria a través del estudio de otros autores ${ }^{2}$. En el presente trabajo trataremos de demostrar la comunidad espiritual que se estableció entre Ayala y los ensayistas argentinos durante el exilio del español en la región del Plata. Centraremos nuestro análisis en Ezequiel Martínez Estrada, Eduardo Mallea y Hector A. Murena, a quienes Ayala dedicó diversos artículos. Estos pensadores manifiestan en sus obras una afinidad ideológica que nos permite comprender el motivo que los hizo atractivos a los ojos del exiliado granadino.

En su libro de memorias Recuerdos y olvidos Francisco Ayala reconoce que le fue muy fácil introducirse en el ambiente de la intelectualidad argentina:

Conocí a numerosas personas del mundo intelectual y literario -prácticamente a "todo el mundo"-. Solíamos pasar muchos ratos en al Embajada de España con el matrimonio Díez-Canedo, amigos amabilísimos a cuyo alrededor se reunían contertulios diversos y, muy asiduamente, Amado Alonso y Pedro Henríquez Ureña... ${ }^{3}$.

En esta época frecuentaban las tertulias y saraos un grupo excepcional de hombres de letras, a los que se denominó "generación de 1927" y entre los que se contaron Jorge Luis Borges, Ezequiel Martínez Estrada o Eduardo Mallea. Con todos ellos entabló amistad Ayala, si bien nos interesa destacar especialmente la relación que mantuvo con quienes se preocuparon por ahondar en la esencia de la Argentina a través de sus ensayos.

\footnotetext{
${ }^{1}$ Varios, Francisco Ayala. Premio Nacional de la Letras Españolas (Barcelona 1988) 57.

${ }^{2}$ Vid. en este sentido el estudio de E. Irizarry Teoría y crítica literaria en Francisco Ayala (Madrid 1971).

${ }^{3}$ F. Ayala, Recuerdos y olvidos (Madrid 1988) 201.
} 
EZEQUIEL MARTINEZ ESTRADA (1895-1964).

La obra de Martínez Estrada atrajo la atención de Ayala por su honestidad intelectual y la aguda y novedosa perspectiva desde la que planteó la realidad rioplatense en sus escritos. En Recuerdos y Olvidos encontramos un testimonio de su trato común:

Otra de las personas con quien entablé y mantuve hasta el final relaciones de buena amistad y gran estimación literaria en Buenos Aires fue Ezequiel Martínez Estrada, que era cuando yo llegué allí uno de los escritores más respetados de Argentina (...).

Publicó por aquellos años otro largo y magnífico ensayo sobre Sarmiento, que yo hube de ponderar en la revista Sur, apasionado discurso donde se esforzaba su autor por desentrañar las raíces histórico-sociales del peronismo rampante (Ayala 1988: 319-320).

Martínez Estrada, a quien Ayala describe con "algo que hacía pensar en los profetas bíblicos; intemperante y violento a veces, y a veces muy sufrido" (ibíd), abordó el conocimiento de la "argentinidad" siguiendo los métodos de la sociología, la antropología cultural y el psicoanálisis en trabajos como La cabeza de Goliat. Microscopía de Buenos Aires (Buenos Aires 1940), Radiografía de la pampa (Buenos Aires 1942) o Cuadrante del pampero (Buenos Aires 1956).

Observamos una primera coincidencia entre la obra del argentino y el español en la aproximación que hacen a la realidad de sus respectivos países a través de la sociología. La interpretación de Martínez Estrada del método de Sarmiento supuso una fundamental contribución a la comprensión de las relaciones existentes entre biografía e historia, como se evidencia en Sarmiento (Buenos Aires 1946), Las invariantes históricas en el Facundo (Buenos Aires 1947) y Meditaciones sarmientinas (Buenos Aires 1968). Ayala comentó el primer libro en su reseña "El Sarmiento de Martínez Estrada", publicada en la prestigiosa revista literaria Sur en la temprana fecha de 1947, lo que sitúa esta recensión como una de las primeras que puso de relieve la importancia de la obra ${ }^{4}$. Interesado en los ensayos cargados de energía y pasión, Ayala intenta ahondar -al igual que Martínez Estradaen la biografía de los autores que investiga. De ahí los elogios que prodigó al libro del argentino:

El acento sincero (...) nos ofrece en el nuevo libro de Martínez Estrada un Sarmiento polémico, problemático, con su grandeza y también con sus fallas (...), un Sarmiento discutible, más aún: discutido, pero muy distinto del pedante gruñón de escayola que ha podido dársenos como imagen entronizada de la infalibilidad sabihonda (Ayala 1972: 1258-1259).

Por otra parte, se manifiesta de acuerdo con el compromiso de Estrada contra la dictadura peronista, a la que hace mención en la reseña de una forma velada:

\footnotetext{
${ }^{4}$ F. Ayala, "El Sarmiento de Martínez Estrada", Sur 150 (1947) 72-74. Citamos la reseña a través de su reedición en Los ensayos. Teoría y crítica literaria (Madrid 1972) 1257-60. Destacamos a continuación otros trabajos que se han ocupado de este mismo aspecto en la obra de Martínez Estrada: M. Bataillon, "Sur l'essence de l'Argentine", Annales 3 (1948) 439-531; J.L. Romero, "Martínez Estrada, un renovador de la exégesis sarmientina", Cuadernos americanos XXXIII:3 (1947) 197-204; J. Rest, "El Sarmiento de Martínez Estrada: un ensayo de autobiografía", Sur 295 (1965) 34-48; J.A. Feustle, "Sarmiento and Martínez Estrada: a concept of Argentine history", Hispania 55 (1972) 446-55; y, finalmente, V. Cvitanovic, "Las formulaciones dualísticas en el ensayo argentino: Sarmiento, Martínez Estrada, Mallea", Criterio (1977) 326-33.
} 
Quiero tan sólo ponderar su significado de verdadero acontecimiento espiritual en momentos como los actuales, críticos en grado sumo (Ayala 1972: 1260) ${ }^{5}$.

EDUARDO MALLEA (1903-1980)

Eduardo Mallea, uno de los más originales pensadores de su tiempo, conciencia de excepción de la realidad de su pueblo, fue otro de los ensayistas argentinos que mereció la atención de Ayala. Aunque sus obras críticas son bastante numerosas nos interesan especialmente Conocimiento y expresión de la Argentina (Buenos Aires 1935) e Historia de una pasión argentina (Buenos Aires 1937), texto este último definido por Francisco Romero como "un nuevo discurso del método" y estudiado por Ayala en "La nación argentina de Eduardo Mallea"6.

En Mallea percibimos de nuevo un gran interés por la sociología, patente en sus apreciaciones acerca de la existencia de una Argentina visible y otra invisible. En esta segunda categoría cree encontrar la autenticidad del ser rioplatense, más allá del fasto y el poder de las clases dominantes, por lo que en su ensayo mantiene una importante perspectiva ético-moral. Coincide por consiguiente con el pensamiento de Martínez Estrada que mereció las alabanzas de Ayala.

En el artículo "La nación argentina de Eduardo Mallea" se destaca que el tema de la identidad nacional vertebra la producción de Mallea:

Los dos títulos reseñados [Conocimiento y expresión de la Argentina e Historia de una pasión argentina] apuntan a él inequívocamente: uno, por los caminos emocionales de la pasión; el otro, por las vías intelectivas del conocimiento. Pero no sólo en estos dos escritos, en todos ellos se encuentra gravitando la presencia de ese tema esencial (Ayala 1972: 1242)

Ayala resume esta "pasión argentina" citando una frase utilizada por Mallea en la novela Fiesta en noviembre: "Este eterno fluctuar, esta cosa atroz de no saber lo que se es, lo que se quiere..." (Ayala 1972: 1243); asimismo, reconoce la profunda relación existente entre novela y ensayo en la obra del argentino:

Con el empleo de sus ficciones, se propone Mallea captar en sus novelas aspectos significativos de la realidad circundante, esa misma realidad patria que en otros de sus libros, más cargados de elementos ideológicos, es perseguida en demanda de una síntesis totalizadora (Ibíd).

\footnotetext{
${ }^{5}$ En Recuerdos y Olvidos leemos el siguiente párrafo al respecto:

Para quien, como yo, había tenido la desagradable oportunidad de presenciar la eclosión y despliegue del nazismo en Alemania, el espectáculo del peronismo presentaba otro aspecto distinto del mismo fenómeno de masas -un fenómeno que yo había estudiado con reiteración casi obsesiva en mis escritos sociológico-políticosSi el totalitarismo italiano era grotesco, y ahora el totalitarismo alemán era siniestro, el totalitarismo argentino sería abyecto (op. cit, p. 369).

${ }^{6}$ Este artículo conoció su primera edición en Histrionismo y representación (Buenos Aires 1944) 213-26. Lo citamos a través de su reedición en Los ensayos, op. cit, 1239-47. Vid. las aproximaciones al mismo tema de F. Romero, "Eduardo Mallea: nuevo discurso del método", en Historia de una pasión argentina (Buenos Aires 1981) 7-12 y C. Ferrándiz Albor, "Historia de una pasión argentina", Cuadernos americanos (1961) 231-48.
} 
Como Ayala, Mallea deja traslucir en sus obras un profundo amor hacia su país, al que critica desdeila posición privilegiada que le ha otorgado el conocimiento profundo de diversas culturas y su reconocido cosmopolitismo espiritual. El autor rioplatense viaja a Europa "para poder contemplar desde fuera su propio país, su Argentina, cuyo acoso es tarea y necesidad de su vida" (Ayala 1972: 1244). De ahí surgió el Nocturno europeo y, tras este libro, sus dos principales ensayos:

Se lanza Mallea a abordar de frente su gran tema. Primero, en un magnífico ensayo, Conocimiento y expresión de la Argentina. Luego, en la Historia de una pasión argentina, clamor y torbellino, impulso interno cuya energía no le consiente acomodarse a canon alguno y que, por ello, establece desde dentro su propia forma (Ibíd).

Ayala alaba el sentimiento de amor visceral a la Argentina que se percibe en el segundo libro:

Quien haya sido atormentado por este amor frenético hacia una patria -amor que envuelve todos los matices del sentimiento, desde el denuesto y el improperio hasta las lágrimas- advertirá todavía contención y freno en Historia de una pasión argentina, esa biografía en que la vida se ha ido sumiendo, despojándose de acontecimientos, para convertirse en puro clamor, un clamor que no tiene más apoyo que la pasión espiritual... (Ayala 1972: 1245-1246)

En las palabras de conclusión determina la naturaleza de la visión ofrecida por Mallea:

Por eso, sin necesidad de apreciar y juzgar su contenido, puedo señalar la importancia de esta visión real-ideal de la nación argentina, en que Mallea analiza sus elementos para establecer un paradigma (Ayala 1972: 1247).

Como los ensayistas argentinos, y desde una postura abierta que lo llevó a negar el concepto de "patria", Ayala intentó establecer el modelo del ser hispánico, manifiesto en sus artículos "La situación literaria de España" o "La excentricidad hispana", en sus comentarios sobre la idiosincrasia nacional presentes en los textos dedicados a autores clásicos (Cervantes, la novela picaresca, Quevedo, Tirso de Molina, Calderón) o en sus estudios sobre hombres de letras más cercanos a su tiempo (Galdós, Unamuno o Antonio Machado).

\section{HECTOR A. MURENA (1923-75)}

H. A. Murena fue uno de los ensayistas más destacados de la generación del 57, coetáneo de figuras tan relevantes en las letras hispanoamericans como Carlos Fuentes, José Donoso y Guillermo Cabrera Infante. Murena impuso al género ensayístico un sello peculiar al establecer un nexo entre sus reflexiones y las tradiciones argentinas. Encontró nuevas perspectivas para explicar el contexto sociohistórico en el que se desarrolló su corta existencia. Fue reconocido como un discípulo aventajado de Martínez Estrada, percibiéndose en los textos de ambos la misma independencia de espíritu y coraje intelectual. A su vez, Murena se reveló como el incitador del "parricidio" simbólico contra las figuras consagradas del pensamiento, entre las que habría que citar al mismo Martínez Estrada, Borges, Mallea o 
Marechal. Certeramente calificó sus ensayos como mitos destinados a explicar las fuerzas humanas y sobrehumanas que mantienen en actividad el mundo americano.

Entre los temas que aborda destacan el del desarraigo originario de los americanos, la ausencia de Dios y la trascendencia o nostalgia del paraíso como esencia del arte ${ }^{7}$. Es autor de obras fundamentales para comprender la identidad latinoamericana como El pecado original de América (Buenos Aires 1954), Homo atomicus (Buenos Aires 1961), Ensayos sobre subversión (Buenos Aires 1962), La cárcel de la mente (Buenos Aires 1971) y La metáfora y lo sagrado (Buenos Aires 1973).

Durante más de treinta años mantuvo una estrecha amistad con Ayala, quien le dedicó un magnífico artículo al recibir la noticia de su muerte ${ }^{8}$. En este sentido "planto" Ayala considera a Murena como uno de los últimos hombres puros, al que "una especie de insensata inocencia que para muchos resultaba insultante le hacía ofrecer al mundo, indefensa, su desnuda autenticidad, esa pureza suya impecable..." (Ayala 1988: 546). Este elogio póstumo se cierra con dos frases significativas del aprecio que sentía por el amigo fallecido: "Su desaparición es una pérdida que no puede contabilizarse. Era único, y lo hemos perdido" (Ayala 1998: 547).

En Recuerdos y olvidos ofrece un retrato de Murena que revela las coincidencias espirituales entre ambos autores:

Murena tenía fama de "hombre difícil". Había ingresado en la vida literaria -irrumpió, sería mejor el verbo- con una sección en la revista Sur a la que dio por título "Los penúltimos días", sección que levantaba ronchas en más de una piel delicada. ...Poco a poco, con avance un tanto premioso, fue creciendo entre nosotros una amistad sólida, firmísima, basada en esa estimación recíproca que no admitía disimulos corteses ni la atenuación piadosa de juicios adversos. (...) En momento alguno dejé de darle mis opiniones sinceras, pues Murena ha sido para mí uno de los muy contados seres a quienes he considerado amigos de veras: nuestra relación era de una confianza total y plena (Ayala 1988: 321-322).

En parecidos términos habla Murena de Ayala al prologar El As de bastos (Buenos Aires 1963). Incluye al amigo en la categoría de los "artistas verdaderos" por aunar la faceta de creador literario con la de pensador, y descubre en Ayala la pureza de espíritu que años más tarde sería reconocida como rasgo esencial de su obra: "Hay un dístico de Hölderlin que aconseja: Si tienes un intelecto y un corazón, muestra solamente uno de los dos. Si los muestras juntos, te maldicen. Tal maldición (...) recae sobre la obra de Francisco Ayala"10.

\footnotetext{
${ }^{7}$ De acuerdo con los últimos motivos reseñados se comprende la importancia que adquirieron en la concepción intelectual de Murena el existencialismo y la filosofía hermética.

${ }^{8}$ Este texto apareció publicado por primera vez en Insula XXX: 346 (1975) 7. Lo citamos a través de su reedición en Recuerdos y olvidos, op. cit, 546-547. Entre otros autores han estudiado la figura de Murena E. Rodríguez Monegal en El juicio de los parricidas (Buenos Aires 1956); Reinaldo Ayerbe-Chaux, en "Aspectos de la temática de H.A. Murena", Symposium 27 (1973) 293-302); y J. O. Jiménez, en "H. A. Murena (19231975); necrología" Revista Iberoamericana 95 (1976), 275-284.

${ }^{9}$ Ibíd, p. 547.

${ }^{10}$ Incluido en Recuerdos y olvidos, op. cit, pp. 543-546.
} 
A lo largo de estas páginas hemos comprobado que Francisco Ayala se interesó por la obra de ensayistas argentinos con los que mantuvo una comunidad de pensamiento y espíritu. Las razones que lo llevaron a analizar las obras de Ezequiel Martínez Estrada, Eduardo Mallea y Héctor A. Murena se pueden sintetizar en su común pasión por la tierra, por la que indagaron sobre la identidad de Argentina y España en múltiples textos; su asumido compromiso político, por el que sufrieron exilio o privación de la libertad intelectual y física, pero al que no renunciaron en ningún momento, siguiendo sus convicciones sobre el papel del hombre de pensamiento en la sociedad; el análisis de su momento histórico-cultural, así como su labor de crítica literaria que aúna la biografía del autor con la discusión del marco humano que sirvió de contexto a la obra investigada.

No puede existir mejor colofón a nuestro comentario que las palabras dedicadas por Murena a Ayala en su prólogo a El As de bastos, donde se manifiestan los elementos comunes a la obra del español y de los ensayistas argentinos:

Mi estupor ante la atmósfera que circunda la obra de Ayala, a la luz de lo que la obra de Ayala es, proviene de la comprobación de que, en medio del asfixiante conformismo pseudorevolucionario que prolifera, tal obra es de verdad revolucionaria. La obra de Ayala es una lucha serena, desilusionada e implacable contra la ignominia de la adaptación, del acostumbramiento a un mundo inhumano... No hay presente hoy para la revolución del arte, y el futuro, la inmortalidad, también parecen haber muerto por largo tiempo. Ayala lo sabe y, no obstante, no ha buscado ninguno de los falsos caminos de escapatoria que a todos se nos ofrecen por doquier. Esa valentía inusitada de artista me hace ver en él a un maestro de quien desearía poder llegar a ser digno alguna vez (Ayala 1988: 546). 